\title{
Structure and Crystallization of Borate-Based Glasses for Machinable Material Applications
}

\author{
Pat Sooksaen, Member, IACSIT
}

\begin{abstract}
This study investigated bulk crystallization at pre-set temperatures of $\mathrm{B}_{2} \mathrm{O}_{3}-\mathrm{SiO}_{2}-\mathrm{Al}_{2} \mathrm{O}_{3}-\mathrm{BaO}-\mathrm{MgO}$ glass system. Heat treatment at pre-set temperature was carried out between 900 and $1200^{\circ} \mathrm{C}$ on clear glasses to form non-transparent glass-ceramics. Structure of glasses were studied by Fourier transform infrared spectroscopy, phase evolution in the bulk crystallized samples was studied by $x$-ray diffraction, microstructures were observed by scanning electron microscope and micro-hardness was measured by Vickers method. Aluminum borate whiskers/rods were in the nano to micro sized regime and dispersed randomly within the remaining glass matrix. Whiskers had different sizes and morphologies depending on the heat treatment temperature. Increasing heat treatment temperature led to an increase in crystal size, length and the formation of hollow tubes. The surface hardness decreased when the morphology changed from fine rods into hollow tubes. The synthesized glass-ceramics in this study can be applied as machinable materials in various applications because their microstructures can resist microcracking.
\end{abstract}

Index Terms-Glass, crystallization, microstructure, whiskers, hardness.

\section{INTRODUCTION}

Fibers and whiskers reinforced glasses and ceramics can lead to significant improvements in mechanical properties, such as increased fracture toughness, bending strength, hardness and thermal shock resistance [1]. The possibility of using whiskers is limited due to the health hazard posed by loose particles with a high aspect ratio shape [2]. Aluminum borate whisker $\left(9 \mathrm{Al}_{2} \mathrm{O}_{3} \cdot 2 \mathrm{~B}_{2} \mathrm{O}_{3}\right)$ is a refractory compound (melting point $1440^{\circ} \mathrm{C}$ ) possessing excellent physical properties, such as low density $\left(2.94 \mathrm{~g} / \mathrm{cm}^{3}\right)$, high hardness, high Young's modulus (400 GPa), high electrical resistivity and low coefficient of thermal expansion [3]. Such characteristics suggest that aluminum borate whisker could be used to reinforce ceramics to give ceramic-ceramic composites with increased fracture toughness and also reinforce light metals such as aluminum alloys. The metal matrix composites (MMCs) can be useful for the automobile and aerospace industries.

Manuscript received February 12, 2012; revised March 24, 2012. This work was supported by the department of Materials Science and Engineering, Silpakorn University and Center of Excellence for Petroleum Petrochemicals and Advanced Materials, Chulalongkorn University.

P. Sooksaen is with the Department of Materials Science and Engineering, Faculty of Engineering and Industrial Technology, Silpakorn University. Nakhon Pathom 73000 Thailand and Center of Excellence for Petroleum, Petrochemicals and Advanced Materials, Chulalongkorn University, Bangkok 10330 Thailand (e-mail: pat@su.ac.th).
Aluminum borate whiskers have been synthesized by various methods such as vapor phase method, solid-state reactive firing and flux method using borates [4-5]. However, the product yields were found to be very low, $10 \%$ or less. The in-situ direct growth of whiskers in a glass to form glass-ceramic is an attractive alternative method. This is analogous to the creation of fluorcansite platelets in toughened glass-ceramics. Unfortunately, oxide systems that can be exploited are limited. Recently, the formation and crystallization behavior of glasses in the $\mathrm{Al}_{2} \mathrm{O}_{3}-\mathrm{B}_{2} \mathrm{O}_{3}-\mathrm{SiO}_{2}$ system has been investigated [6], showing that whisker-shaped aluminum borate crystals can be obtained after thermal treatment.

This study investigated a specially formulated glass compositions based on a composition similar to that proposed by Lee et al. [7]. In this further compositional modification, both $\mathrm{B}_{2} \mathrm{O}_{3}$ and $\mathrm{SiO}_{2}$ act as glass forming oxides. The effects of varying mole ratio between the two glass forming oxides on the materials properties were studied. The effect of varying $\mathrm{B}_{2} \mathrm{O}_{3} / \mathrm{SiO}_{2}$ ratio on the crystallization of aluminum borate whisker glass-ceramics has never been investigated elsewhere. The in-situ crystallization of an aluminum borosilicate glass was carried out above glass transition temperature of the as-annealed glasses at pre-set tmperatures. Phase evolution, microstructures and their related microhardness values were investigated.

\section{MATERIALS AND METHODS}

Glass compositions according to Table $\mathrm{I}$ in the $\mathrm{B}_{2} \mathrm{O}_{3}-\mathrm{SiO}_{2}$ $-\mathrm{Al}_{2} \mathrm{O}_{3}-\mathrm{BaO}-\mathrm{MgO}$ glass system were prepared from high purity $(\geq 99 \%)$ raw materials: silica sand, $\mathrm{B}_{2} \mathrm{O}_{3}, \mathrm{Al}_{2} \mathrm{O}_{3}$, $\mathrm{BaCO}_{3}$ and $\mathrm{MgO}$. Melting was carried out in an alumina crucible at $1500^{\circ} \mathrm{C}$ for $1 \mathrm{~h}$ using electric furnace. The glass melt was cast onto a steel block and quickly transferred into a muffle furnace for annealing at $500^{\circ} \mathrm{C}$ for $2 \mathrm{~h}$ then furnace cooled to room temperature. Glass block was cut into small pieces for further characterization. Fourier Transform Infrared (FT-IR) absorption spectra of the annealed glasses were obtained at room temperature in the wavenumber range of 4000-400 cm $\mathrm{cm}^{-1}$ using a Fourier transform infrared spectrometer (Vertex 70, Bruker). The samples were ground into fine powders $(<180 \mu \mathrm{m})$ and then mixed with $\mathrm{KBr}$ powder in a very precise amounts using powder: $\mathrm{KBr}$ ratio of $1: 9$; subsequently, the mixtures were uniaxially pressed to form clear homogeneous discs. The FT-IR measurements were carried out immediately after preparing the discs to avoid moisture absorption. Chemical bonds in different environments will absorb varying intensities and at varying frequencies. The frequencies at which there are absorptions 
of IR radiation can be correlated directly to bonds within the substance. Single-step heat treatment was used to crystallize glasses at temperature between 900 and $1200^{\circ} \mathrm{C}$ following the differential thermal analysis (DTA) data preliminarily performed on glass powders using a Perkin Elmer DTA7 with heating rate of $5^{\circ} \mathrm{C} / \mathrm{min}$. The isothermal crystallization was pre-set to the required temperature before inserting the samples into the furnace. The isothermal holding time was $4 \mathrm{~h}$ after that the furnace was switched off and cooled to room temperature. X-ray Diffraction (XRD) was used to identify phases in crystallized samples. XRD study was performed on a Rigaku Miniflex II from $10^{\circ}$ to $80^{\circ} 2 \theta$ with a scan speed of $1 \%$ min and step size $0.02^{\circ}$ using $\mathrm{Cu} \mathrm{K} \alpha$ radiation. Glass-ceramic samples were polished to mirror finish surfaces of $1 \mu \mathrm{m}$ using $\mathrm{SiC}$ papers and diamond paste. Chemical etching with $0.2 \% \mathrm{HF}$ for $30-60$ seconds was required to remove residual glass and discern microstructure. Microstructural study was performed by a Camscan MX2000 scanning electron microscope (SEM) at $10-20 \mathrm{kV}$. Samples were ultrasonically cleaned and gold-coated for conductive layer by a Cressington Sputter Coater 108. Hardness of glass-ceramics was obtained from a HV-1000B Vickers microhardness tester with a load of $1 \mathrm{kgf}(9.81 \mathrm{~N})$ on a mirror finish surface.

\begin{tabular}{cccccc} 
TABLE I: GLASS COMPOSITIONS MELTED IN MOL \% OXIDE \\
\cline { 2 - 6 } Glass & $\mathbf{B}_{\mathbf{2}} \mathbf{O}_{\mathbf{3}}$ & $\mathbf{S i O}_{\mathbf{2}}$ & $\mathbf{A l}_{\mathbf{2}} \mathbf{O}_{\mathbf{3}}$ & $\mathbf{B a O}$ & $\mathbf{M g O}$ \\
\hline G1 & $\mathbf{5 0}$ & $\mathbf{2 3}$ & $\mathbf{1 7}$ & $\mathbf{5}$ & $\mathbf{5}$ \\
$\mathbf{G 2}$ & $\mathbf{5 2}$ & $\mathbf{2 1}$ & $\mathbf{1 7}$ & $\mathbf{5}$ & $\mathbf{5}$ \\
$\mathbf{G 3}$ & $\mathbf{5 4}$ & $\mathbf{1 9}$ & $\mathbf{1 7}$ & $\mathbf{5}$ & $\mathbf{5}$ \\
\hline
\end{tabular}

\section{RESULTS AND DISCUSSION}

This study showed that different $\mathrm{B}_{2} \mathrm{O}_{3} / \mathrm{SiO}_{2}$ ratio in the proposed glass compositions affected the structure and properties of glasses and also the crystallized glass samples. The preliminary investigation by differential thermal analysis of the as-annealed glasses indicated two distinct thermal transitions. The first endotherm was detected from the slope change of derivative curve and corresponds to the glass transition temperature, $\mathrm{T}_{\mathrm{g}}$. In bulk crystallized glass-ceramic, nucleation of crystals occurs above $T_{g}$. Exothermic peak was correlated with the crystallization of crystalline aluminum borate phase from the glass matrix. It was found that both the endotherm and exotherm shifted to lower temperatures with increasing in the $\mathrm{B}_{2} \mathrm{O}_{3} / \mathrm{SiO}_{2}$ ratio. The glass transition temperatures were $646^{\circ} \mathrm{C}, 620^{\circ} \mathrm{C}$ and $598^{\circ} \mathrm{C}$ for glass $\mathrm{G} 1, \mathrm{G} 2$ and G3, respectively. The exothermic crystallization peaks were $825^{\circ} \mathrm{C}, 812^{\circ} \mathrm{C}$ and $800^{\circ} \mathrm{C}$ for glass $\mathrm{G} 1, \mathrm{G} 2$ and $\mathrm{G} 3$, respectively. The increase in $\mathrm{B}_{2} \mathrm{O}_{3}$ content leads to lower $\mathrm{T}_{\mathrm{g}}$ and suggests that crystallization and crystal growth in the glass can be improved.

The Fourier transform infrared absorption spectra of as-annealed glass G1, G2 and G3 are shown in Fig.1. IR absorption peaks and vibration types of glasses G1, G2 and G3 were summarized in Table II. All annealed glasses showed four main absorption peaks which are related to different vibration types. It was found that increasing in the $\mathrm{B}_{2} \mathrm{O}_{3} / \mathrm{SiO}_{2}$ ratio in the parent glass compositions resulted in broadening of $\mathrm{B}-\mathrm{O}-\mathrm{B}$ stretching vibration in $\left[\mathrm{BO}_{3}\right]$ triangles and the peak slightly shifted to lower wavenumber from 1428 (for G1) to 1404 (for G3) $\mathrm{cm}^{-1}$. The bending vibration of $\mathrm{B}-\mathrm{O}-\mathrm{B}$ in $\left[\mathrm{BO}_{3}\right]$ triangles shifted slightly to higher wavenumber from 687 (for G1) to 694 (for G3) $\mathrm{cm}^{-1}$. The stretching vibration of $\mathrm{B}-\mathrm{O}-\mathrm{B}$ bond in $\left[\mathrm{BO}_{4}\right]$ tetrahedron shifted to lower wavenumber from G1 to G3 suggesting that this type of vibration was more likely in glass G1 as opposed to glass $\mathrm{G} 3$. The $\left[\mathrm{BO}_{4}\right]$ tetrahedra could dominate the glass structure in the glass composition with lower $\mathrm{B}_{2} \mathrm{O}_{3} / \mathrm{SiO}_{2}$ ratio. In additions, the vibration of $\mathrm{O}-\mathrm{Si}-\mathrm{O}$ bond was easier for glass G3 compared to the other two compositions. The absorption peak shifted to higher wavenumber from 343 (for $\mathrm{G} 1$ ) to 436 (for G2) and 448 (for G3) $\mathrm{cm}^{-1}$. This suggests that the structure of glass G3 was less rigid [6] and hence would lead to easier nucleation and growth of aluminum borate whiskers.

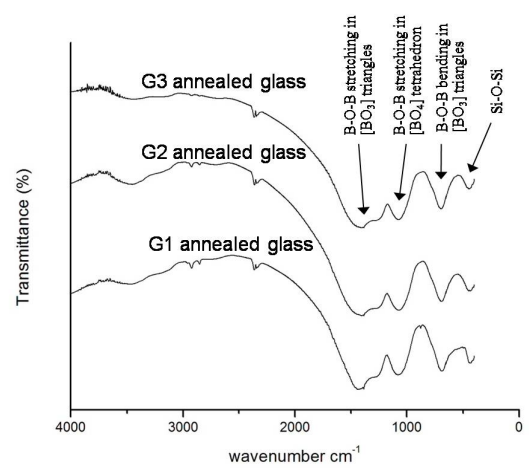

Fig. 1. FT-IR absorption peaks of as-annealed glasses G1, G2 and G3.

\begin{tabular}{ccccc} 
TABLE II: VIBRATION TYPES AND IR ABSORPTION OF GLASS G1, G2 AND G3 \\
\cline { 2 - 5 } Glass & $\begin{array}{c}\text { B-O-B } \\
\text { stretching in } \\
{\left[\mathrm{BO}_{3}\right]}\end{array}$ & $\begin{array}{c}\text { IR-O-B } \\
\text { stretching in } \\
{\left[\mathrm{BO}_{4}\right]}\end{array}$ & $\begin{array}{c}\mathrm{B}-\mathrm{O}-\mathrm{B} \\
\text { bending in } \\
{\left[\mathrm{BO}_{3}\right]}\end{array}$ & Si-O-Si \\
tetrahedron & triangles & \\
\hline G1 & 1428 & 1079 & 687 & 434 \\
G2 & 1404 & 1073 & 690 & 436 \\
G3 & 1404 & 1070 & 694 & 448 \\
\hline
\end{tabular}

At each heat treatment temperature, all glass compositions crystallized to give the same $\mathrm{X}$-ray diffraction (XRD) peaks therefore only glass G3 data were reported. XRD analysis in Fig. 2 showed example of a broad diffraction pattern of an as-annealed glass G3 confirming amorphous characteristic. Isothermal heat treatment revealed crystalline phases of $\mathrm{Al}_{4} \mathrm{~B}_{2} \mathrm{O}_{9}, \mathrm{Al}_{18} \mathrm{~B}_{4} \mathrm{O}_{33}$ and $\mathrm{BaAl}_{2} \mathrm{~B}_{4} \mathrm{O}_{10}$. The amount and type of crystalline phases formed depended on the heat treatment temperature. The glass crystallized significantly with increasing heating temperature to form crystalline aluminum borate crystals within glass matrix. At temperatures between 900 and $1000^{\circ} \mathrm{C}, \mathrm{Al}_{4} \mathrm{~B}_{2} \mathrm{O}_{9}$ (JCPDS PDF\#29-0010) was the only phase, while from above $1100^{\circ} \mathrm{C}, \mathrm{Al}_{18} \mathrm{~B}_{4} \mathrm{O}_{33}$ (JCPDS, PDF\#29-0009) was also present in addition to the $\mathrm{Al}_{4} \mathrm{~B}_{2} \mathrm{O}_{9}$ phase which decreased in diffraction peak heights possibly due to phase transformation into a more thermodynamically stable structure. In accordance with the phase diagram [8], the $\mathrm{Al}_{18} \mathrm{~B}_{4} \mathrm{O}_{33}$ phase is expected to form at about $1040^{\circ} \mathrm{C}$ from the decomposition or transformation of $\mathrm{Al}_{4} \mathrm{~B}_{2} \mathrm{O}_{9}$. The lower temperature phase of aluminum borate is retained to higher temperatures (in the glass-ceramic) because of limited mass transport between the glassy phase and the transforming 
whiskers. In the case of the aluminum borate in the form of powders, boron oxide evolution can occur without such a kinetic limitation.

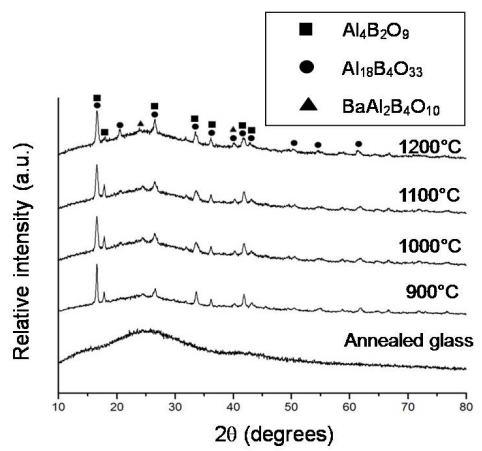

Fig. 2. XRD patterns of as-annealed glass G3 and its crystallized samples between 900 and $1200^{\circ} \mathrm{C}$.

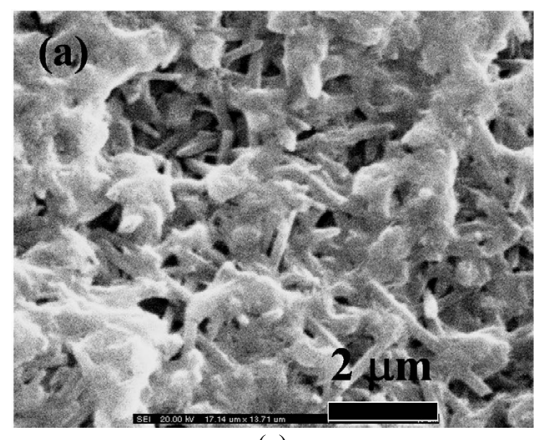

(a)

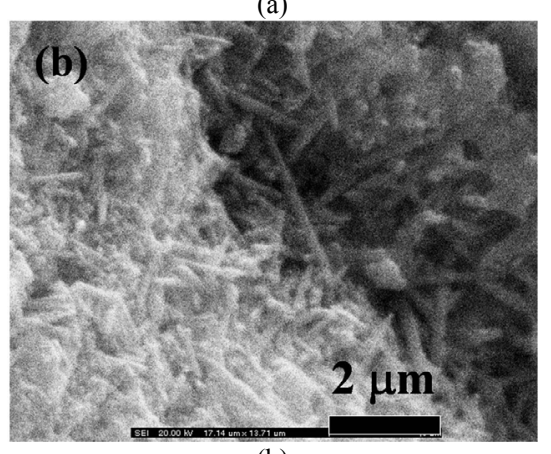

(b)

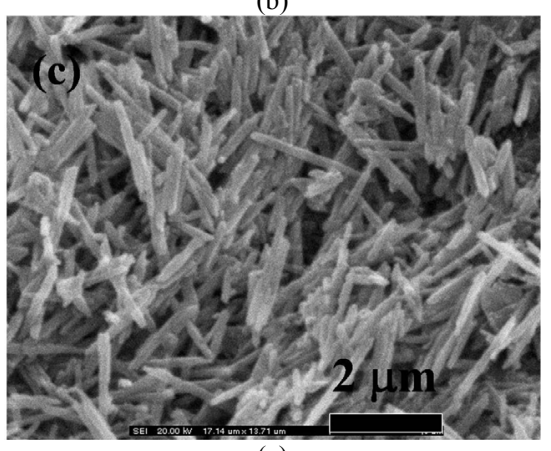

(c)

Fig. 3. Glass-ceramics prepared at $1000^{\circ} \mathrm{C}$ for 4 hours (a) glass G1 (b) glass $\mathrm{G} 2$ and (c) glass $\mathrm{G} 3$.

Microstructures of crystallized glass samples at $1000^{\circ} \mathrm{C}$ for $4 \mathrm{~h}$ are shown in Fig.3. At this temperature the size of aluminum borate whiskers crystallized from G1, G2 and G3 (Figs.3a-c) seemed to be unaffected by the heat treatment temperature. The length of whiskers in crystallized glass sample at $1000^{\circ} \mathrm{C}$ was shorter than $2 \mu \mathrm{m}$ and most of them were in sub-micron regime. The diameter of the rods/whiskers was less than $100 \mathrm{~nm}$. At the same etching conditions more residual glassy phase was observed in G1 composition. This could be related to the more rigid structure of the glass and hence difficulty for crystallization process. When the heat treatment temperature was increased to $1200^{\circ} \mathrm{C}$ the whiskers or rod-like crystals increase in size significantly. Microstructures for heat treated samples of G1, $\mathrm{G} 2$ and $\mathrm{G} 3$ at $1200^{\circ} \mathrm{C}$ are shown in Fig.4a-c. The length and diameter increased dramatically and varied from $5-10 \mu \mathrm{m}$ in length. Whiskers in samples at $1000^{\circ} \mathrm{C}$ can be correlated with $\mathrm{Al}_{4} \mathrm{~B}_{2} \mathrm{O}_{9}$ phase according to XRD data. For samples heat treated at $1200^{\circ} \mathrm{C}$, whiskers could be of either $\mathrm{Al}_{4} \mathrm{~B}_{2} \mathrm{O}_{9}$ or $\mathrm{Al}_{18} \mathrm{~B}_{4} \mathrm{O}_{33}$ or both. Interestingly, glass composition with higher $\mathrm{B}_{2} \mathrm{O}_{3} / \mathrm{SiO}_{2}$ ratio led to the hollow tube morphology of the aluminum borate phase (Fig.4b). Some hollow tubes grew in expense of the others and they were surrounded by smaller whiskers which grew slower. The mechanism of formation is not yet known and has not been discussed in any related literature. Glass $\mathrm{G} 3$ with the highest $\mathrm{B}_{2} \mathrm{O}_{3} / \mathrm{SiO}_{2}$ ratio (Fig.4c) showed partially melting of the large hollow tubes. This indicates that the composition of this phase may be slightly different from that in glass G1 and glass G2.
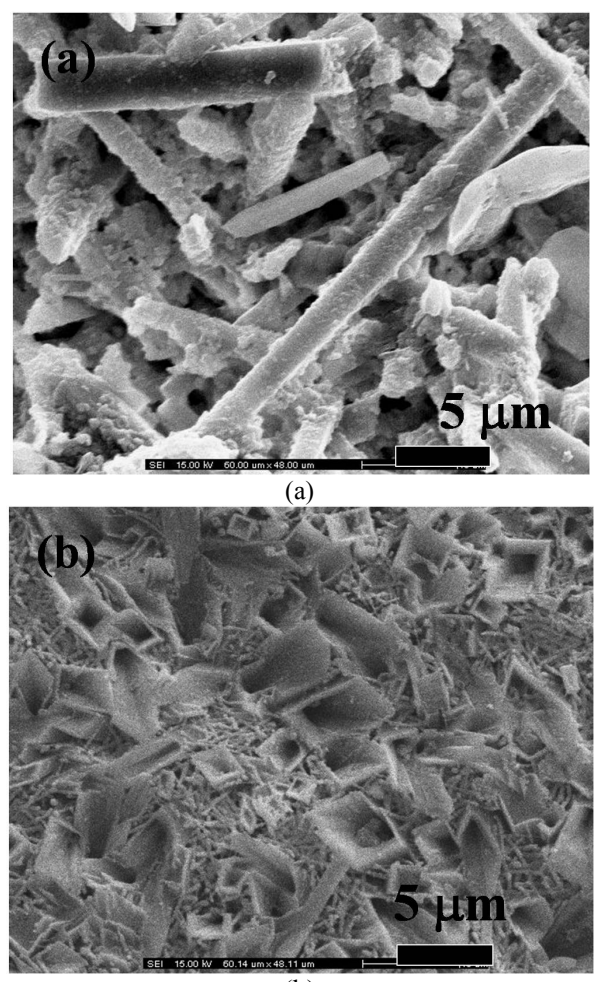

(b)

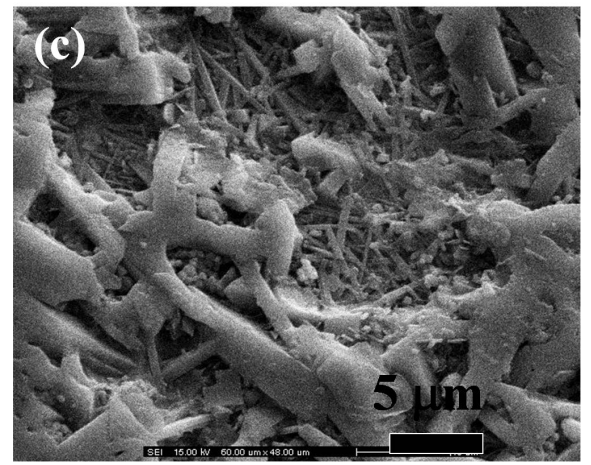

(c)

Fig. 4. Glass-ceramics prepared at $1200^{\circ} \mathrm{C}$ for 4 hours (a) glass G1 (b) glass $\mathrm{G} 2$ and (c) glass G3. 
In terms of the mechanical properties, surface micro-hardness was measured and calculated from standard Vickers formula: $\mathrm{HV}=1.8544 \mathrm{P} / \mathrm{d}^{2}$ where $\mathrm{P}$ is the indentation load and $\mathrm{d}$ is the diagonal of the indentation. The data are shown in Fig.5. The hardness values of the base glasses were reported at $25^{\circ} \mathrm{C}$. It was found that the average values were highest at $25^{\circ} \mathrm{C}$ treat treatment. This was related to the fine aluminum borate whiskers in the microstructure. The dropping trend of the hardness value could be related to the larger crystal size. Especially the formation of hollow tubes may have generated large internal stresses and microcracks along the tubes upon indentation. This led to easy paths for crack propagation. Samples having smaller whisker crystals randomly oriented gave the interlocking microstructure which resulted in higher hardness [9].

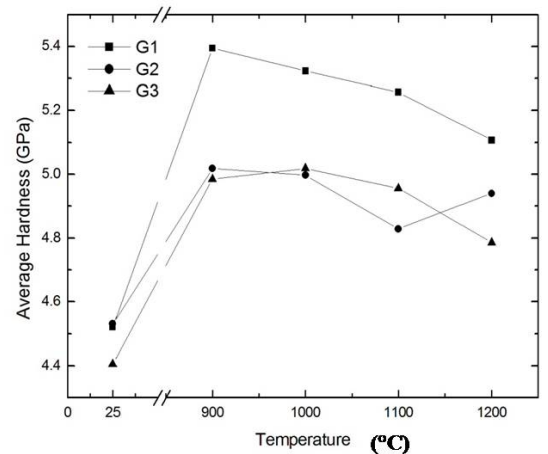

Fig. 5. Surface microhardness of the as annealed and the heat treated samples of $\mathrm{G} 1, \mathrm{G} 2$ and $\mathrm{G} 3$.

\section{CONCLUSIONS}

The proposed aluminum borosilicate glass system crystallized via a bulk crystallization mechanism, resulting in an increasing amount of aluminum borate whiskers with increasing heating temperature. Different phases were found for samples heat treated at different temperatures. Microstructures and hardness values were effectively influenced by the ratio of $\mathrm{B}_{2} \mathrm{O}_{3} / \mathrm{SiO}_{2}$ and the heat treatment temperature. All crystallized glass samples showed randomly oriented whisker crystals/rods with uniform microstructure.

\section{ACKNOWLEDGMENT}

The authors would like to thank department of materials science and engineering, silpakorn university and center of excellence for petroleum petrochemicals and advanced materials, chulalongkorn university for financial support and facilities for experimental work.

\section{REFERENCES}

[1] P. F. Becher, C. H. Hsueh, P. Angelini, and T. N. Tiegs, "Toughening behavior in whisker-reinforced ceramic matrix composites," J. Am. Ceram. Soc., vol.. 71, pp.1050-1061, 1988.

[2] N. A. Travitzky, "Mechanical properties and microstructure of mullite whisker-reinforced magnesium aluminosilicate glass with cordierite composition," J. Mater. Sci. Lett., vol. 17, pp.1609-1611, 1998.

[3] J. X. Li, T. Narita, J. Ogawa, and M. Wadasako, "In situ synthesis of porous ceramics with a framework structure of aluminium borate whisker,” J. Mater. Sci., vol. 33, pp. 2601-2605, 1998.

[4] K. Okada and N. Otuska, "Synthesis of mullite whiskers and their application in composites," J. Am. Ceram. Soc., vol. 74, pp. 2412-2418, 1991.

[5] S. Hashimoto and A. Yamaguchi, "Synthesis of MgAl2O4 whiskers by oxidation-reduction method," J. Am. Ceram. Soc., vol. 79, pp. 491-494, 1996.

[6] Y. Cheng, H. Xiao, C. Shuguang, and B. Tang, "Structure and crystallization of B2O3-A12O3-SiO2 glass," Phys. B 404, pp.1230-1234, 2009.

[7] H. K. Lee, S. Zerbetto, P. Colombo, and C.G. Pantano, "Glass-ceramics and composites containing aluminum borate whiskers," Ceramics International, vol. 36, pp.1589-1596, 2010.

[8] S. B. Ray, "Preparation and characterization of aluminum borate," $J$. Am. Ceram. Soc., vol. 75, pp.2605-2609, 1992.

[9] G. Beall, "Design of glass-ceramics," Solid State Sci., vol. 3, pp.333-354, 1989.

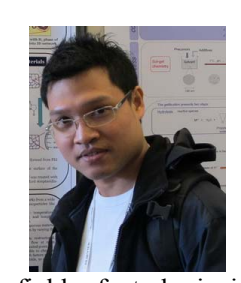

Pat Sooksaen is the corresponding author and he currently works as a lecturer at Silpakorn University, Sanachandra palace campus, Thailand. He obtained a first class BSc degree honor in Materials Science and Engineering from the University of Manchester Institute of Science and Technology (UMIST) in 2007. He later obtained a PhD in Engineering Materials from the University of Sheffield in 2007. The author's major field of study is in engineering ceramics and glasses. He is currently interested in nanotechnology and nano-materials. Previous publications: P. Sooksaen and I. M. Reaney, "Thermal analysis and phase evol.ution of ferroelectric $\mathrm{PbTiO}_{3}$ obtained from silicate and borate based glasses," Journal of Materials Science, Vol.43, pp.1265 - 1269, 2008. P. Sooksaen, I. M. Reaney and D. C. Sinclair, "Crystallization and dielectric properties of borate-based ferroelectric $\mathrm{PbTiO}_{3}$ glass-ceramics," Journal of Electroceramics, Vol.19, pp.221-228, 2007. P. Sooksaen, I. M. Reaney and D. C. Sinclair, "Engineered sintering aids for PbO-based electroceramics," Journal of Electroceramics, Vol.18, pp.77-85, 2007. 